\title{
Escala de violência intrafamiliar e escolar usando a Teoria de Resposta ao Item
}

\author{
Intra-family and school violence scale \\ using the Item Response Theory
}

Thanise Sabrina Souza Santos (https://orcid.org/0000-0003-4087-1815) ${ }^{1}$

Dalton Francisco de Andrade (https://orcid.org/0000-0002-4403-980X) ${ }^{2}$

Antonio Cezar Bornia (https://orcid.org/0000-0003-3468-7536) ${ }^{3}$

Wolney Lisboa Conde (https://orcid.org/0000-0003-0493-134X) ${ }^{4}$

Betzabeth Slater Villar (https://orcid.org/0000-0003-2511-1770) ${ }^{4}$

${ }^{1}$ Programa de Pós-

Graduação de Nutrição em Saúde Pública, Universidade de São Paulo (USP). Av. Dr. Arnaldo 715, Cerqueira Cesar. 01246-904 São Paulo SP Brasil.

thanisesouza@gmail.com

${ }^{2}$ Departamento de

Informática e Estatística,

Universidade Federal de

Santa Catarina (UFSC).

Florianópolis SC Brasil.

${ }^{3}$ Departamento de

Engenharia de Produção

e Sistemas, UFSC.

Florianópolis SC Brasil.

${ }^{4}$ Departamento de Nutrição,

Faculdade de Saúde Pública,

USP. São Paulo SP Brasil.

\begin{abstract}
Violence is a global public health problem and may be of a physical, sexual, or psychological nature, or due to negligence. In order to evaluate this situation, instruments are needed that can assess this widely diverse scenario. The scope of this research was to develop a scale to evaluate intra-family and school violence. In this study, the questionnaire on violence proposed by the World Health Organization and included in the Health and Nutrition Monitoring System - Nutrition of Students, was used. The questionnaire was applied to adolescents of both sexes, enrolled in public schools in the city of Piracicaba, Brazil, in 2014. The gradual response model of the Item Response Theory (IRT) was used to create the scale and analyze the questions contained in the questionnaire. The scale presented more precise information for levels of above average violence, implying greater applicability for populations at risk of intra-family and school violence. The use of the scale is proposed as a new approach to assess intra-family and school violence in future studies. Key words Violence, Bullying, Family relationships
\end{abstract}

Resumo A violência é um problema de saúde pública mundial, podendo ser de ordem física, sexual, psicológica ou por negligência e, para sua avaliação, são necessários instrumentos capazes de medir toda esta diversidade. O objetivo desta pesquisa foi desenvolver uma escala para avaliar a violência intrafamiliar e escolar. Foi utilizado o questionário de violência, proposto pela Organização Mundial de Saúde e incluído no Sistema de Monitoramento da Saúde e Alimentação - Nutrição do Escolar. O questionário foi aplicado em adolescentes de ambos os sexos, matriculados em escolas públicas da cidade de Piracicaba, Brasil, em 2014. O modelo de resposta gradual da Teoria de Resposta ao Item (TRI) foi utilizado para criação da escala e análise das perguntas do questionário. A escala apresentou informação mais precisa para níveis de violência acima da média, sugerindo uma maior aplicabilidade para populações em risco de violência intrafamiliar e escolar. Sugere-se o uso da escala como nova abordagem para avaliar a violência intrafamiliar e escolar nos próximos estudos.

Palavras-chave Violência, Bullying, Relações familiares 


\section{Introdução}

A violência é um problema de saúde pública mundial definida pela Organização Mundial de Saúde como: "uso da força física ou do poder real ou em ameaça, contra si próprio, contra outra pessoa, ou contra um grupo ou uma comunidade, que resulte ou tenha qualquer possibilidade de resultar em lesão, morte, dano psicológico, deficiência de desenvolvimento ou privação"'.

Os atos de violência estão associados a problemas de ordem física, sexual, psicológica ou por negligência. Um olhar restrito às lesões físicas ou morte limita a compreensão do impacto da violência em nível individual e de população ${ }^{2}$. Apesar de ser um processo social, a área da saúde é corresponsável no cuidado dos agravos físicos e emocionais decorrentes da violência, definindo as medidas preventivas e de promoção de um bem estar individual e coletivo ${ }^{3}$.

No Brasil, 7,4\% dos adolescentes do 90 ano do ensino fundamental relatam que sempre ou quase sempre se sentiram humilhados por provocações dos colegas e $14,5 \%$ afirmam já terem sido agredidos por familiares nos 30 dias anteriores à pesquisa ${ }^{4}$. Em âmbito internacional, 16,3\% e $18,4 \%$ dos jovens relatam já terem sofrido agressão física e emocional, respectivamente, e $29,4 \%$ das mulheres com 15 a 19 anos relatam ter sido vítimas de abuso sexual pelo seu parceiro ${ }^{5,6}$.

Os números de agressões entre os adolescentes são destaque nas pesquisas, incluindo os ambientes intrafamiliar e escolar. É nesta fase da vida que se observa um aumento progressivo do nível de violência, com maiores chances de persistir durante a vida. Observa-se um ciclo de difícil intervenção e com impacto na qualidade de vida em curto e longo prazo ${ }^{2,7}$.

O planejamento e efetividade das políticas públicas dependem da precisão de estatísticas que não são mensuradas diretamente, mas a partir de um conjunto de fatores sociais, econômicos, psicológicos e culturais. Tradicionalmente, os instrumentos utilizados para mensurar o nível de violência na população têm como base a Teoria Clássica de Medidas que permite conhecer apenas o percentual de resposta por questão avaliada. Para medidas mais específicas, a Teoria de Resposta ao Item (TRI) apresenta-se como uma alternativa que complementa a abordagem clássica acrescentando informações quanto à discriminação e dificuldade de cada pergunta ${ }^{8}$.

O nível de violência de um indivíduo ou população apresenta um perfil cumulativo, ou seja, é maior conforme aumenta a frequência que é vítima de alguns atos de violência. A Teoria de Resposta ao Item permite trabalhar com modelos acumulativos, sendo que a probabilidade de marcar a maior frequência de um evento será maior com o aumento do nível do traço latente medido $^{8,9}$.

Os instrumentos de mensuração da violência intrafamiliar e escolar estão mais direcionados às lesões físicas, negligenciando aquelas de ordem mais emocional. É necessário um método que permita medir o nível de violência intrafamiliar e escolar em toda a sua diversidade, além de fornecer uma medida mais precisa. Este trabalho teve como objetivo desenvolver uma escala para avaliar a violência intrafamiliar e escolar a partir da Teoria de Resposta ao Item.

\section{Métodos}

Os dados do presente estudo são provenientes do desenho transversal do inquérito intitulado $D e$ terminantes do risco de obesidade entre adolescentes a partir de inquérito de escolares com amostra mista: transversal e longitudinal (IAP-SP). O IAP -SP corresponde à terceira onda de inquéritos realizados no município de Piracicaba, São Paulo, Brasil, com adolescentes escolares. Foi realizada uma amostragem probabilística das escolas utilizando dois critérios de estratificação: geográfico (centro e bairros periféricos) e tipo de administração escolar (público e particular). O IAP-SP teve apoio financeiro da Fundação de Amparo à Pesquisa do Estado de São Paulo (FAPESP) e foi aprovado pelo Comitê de Ética na Pesquisa da Faculdade de Saúde Pública da Universidade de São Paulo.

\section{Instrumento}

Foi utilizado o questionário de violência, proposto pela Organização Mundial de Saúde ${ }^{10}$, traduzido e incluído no Sistema de Monitoramento da Saúde e Alimentação - Nutrição do Escolar ${ }^{11}$. Este questionário é composto por dez perguntas com quatro a cinco alternativas de respostas ordinais (Figura 1).

A Teoria de Resposta ao Item pressupõe que a probabilidade de responder a um item deve ser independente de respostas a outros itens pressuposto de invariância local ${ }^{8,9}$. A pergunta "Quando teus pais te bateram pela última vez?" depende de resposta à pergunta anterior ("Seus pais já bateram em você?"). Como ambas se referem ao adolescente ter apanhado dos pais, para 
Questionário 10- Violência

Este questionário é sobre questões muito pessoais. Você não é obrigado(a) a responder, portanto, é muito importante que você complete todas as questões.

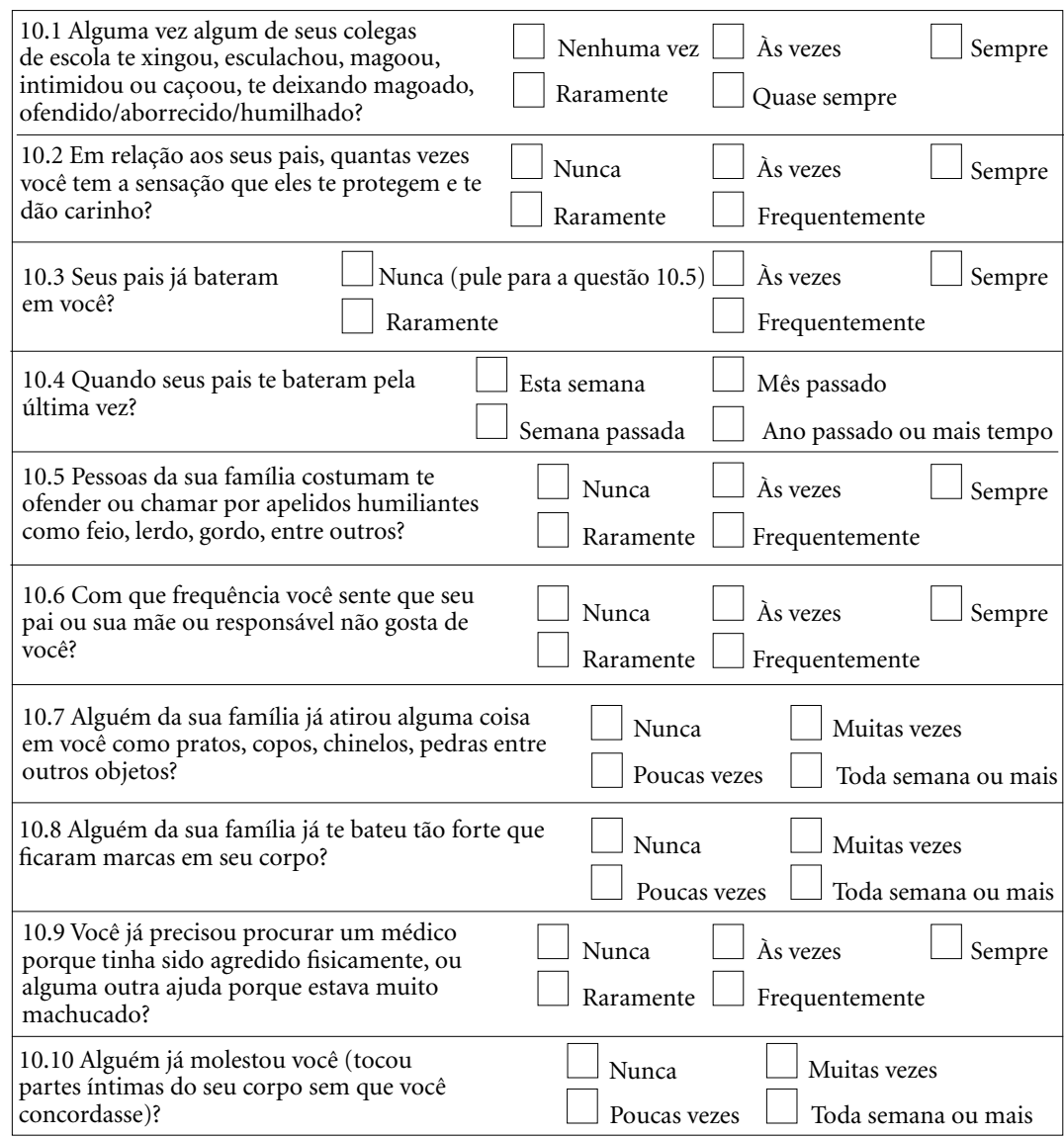

Figura 1. Questionário de violência traduzido.

desenvolver a escala, estas duas perguntas foram agrupadas. Assim, foi analisado um total de nove perguntas para a construção da escala de violência intrafamiliar e escolar.

\section{Análises dos dados}

Em média, aproximadamente 1\% dos indivíduos não respondeu a alguma questão, sendo que este percentual de não resposta variou de 0,47 a $2,27 \%$. Estes casos sem resposta no banco de dados foram codificados como dados não apresentados e não submetidos a um processo de imputação. De acordo com o pressuposto de invariância local da TRI, este tratamento dos casos sem resposta não afeta os cálculos dos parâmetros dos itens e dos escores dos respondentes ${ }^{8}$.
Após esta organização dos dados, prosseguiuse com o estudo da dimensionalidade do questionário pela análise fatorial de informação completa no pacote mirt do ambiente R Project (https:// www.r-project.org/). Foi escolhido o modelo com melhor ajuste, comparando os critérios AIC (Akaike Information Criterion) e BIC (Bayesiano Information Criterion). Foram considerados pertencentes à estrutura fatorial aqueles itens com comunalidades e cargas fatoriais adequadas ${ }^{12}$. A partir destas análises, foi possível verificar se alguma pergunta do questionário estava ou não relacionada com outro traço latente que não o de interesse.

Por fim, a consistência interna dos itens foi avaliada pelo alpha de Cronbach padronizado no pacote psych do ambiente R Project. Foi conside- 
rada uma consistência interna adequada quando alpha de Cronbach maior do que $0,7^{12}$, sendo avaliado também o efeito da exclusão de cada item sobre o valor de alpha. No pacote mirt, a qualidade do ajuste do modelo foi estudada pelos índices de ajustes incrementais: Índice de ajuste comparativo (CFI) e Índice de Tucker Lewis (TLI), e índice de ajuste baseado nos resíduos: Raiz do erro quadrático médio de aproximação (RMSEA). Foi considerado ajuste do modelo se observados valores CFI e TLI superiores 0,90 e RMSEA inferior a $0,05^{13}$.

Para a criação da escala, foi utilizada a TRI, com o modelo de resposta gradual de Samejima ${ }^{14}$ que é representado pela equação a seguir:

$$
\mathrm{P}_{\mathrm{i}, \mathrm{k}}(\theta)=\frac{1}{1+\mathrm{e}^{-\mathrm{a}_{\mathrm{i}}\left(\theta_{\mathrm{j}}-\mathrm{b}_{\mathrm{i}, \mathrm{k}}\right)}}-\frac{1}{1+\mathrm{e}^{-\mathrm{a}_{\mathrm{i}}\left(\theta_{\mathrm{j}}-\mathrm{b}_{\mathrm{i}, \mathrm{k}+1}\right)}}
$$

onde: $\mathrm{P}_{\mathrm{i}, \mathrm{k}}\left(\theta_{\mathrm{j}}\right)$ - probabilidade do indivíduo $j$, ao responder à pergunta $i$, marcar a categoria $\mathrm{k}$ ou uma maior; $\mathrm{a}_{\mathrm{i}}$ - parâmetro de discriminação da pergunta $i ; \mathrm{b}_{\mathrm{i}, \mathrm{k}}$ - parâmetro de dificuldade da categoria $\mathrm{k}$ da pergunta $i ; \theta_{\mathrm{j}}$ - escore do indivíduo $j$.

A calibração dos parâmetros dos itens e a estimação dos escores foram realizadas no pacote mirt. Para cada uma das perguntas, foi estimado um parâmetro de discriminação $(a)$ que identifica a qualidade da pergunta em discriminar indivíduos que sofreram menor ou maior nível de violência. Perguntas com melhor discriminação apresentam maiores valores de $a^{8}$. Foi considerada uma discriminação adequada quando $a>$ $0,70^{15}$. Com exceção da primeira categoria, foi estimado um parâmetro de dificuldade $(b)$ para cada categoria de resposta, sendo $b_{2}, b_{3}$ e $b_{4}$ os valores de $b$ para as categorias 2,3 e 4 , respectivamente. Os parâmetros $b_{2}, b_{3}$ e $b_{4}$ identificam os pontos na escala no qual a probabilidade de satisfazer às condições do item seja maior ou igual a $50 \%$ de resposta à respectiva categoria. As estimativas de $b$ foram estimadas na mesma unidade de medida que os escores, que foram calculados na escala $(0,1)$ com média igual a zero e desvio -padrão igual a um? .

A distribuição dos parâmetros $b$ e seus respectivos erros-padrão foram analisados para verificar valores muito discrepantes, o que poderia indicar falha no processo de calibração. Em casos de valores de $b$ inferiores a -3 ou superiores a $+3 \mathrm{e}$ respectivos erros-padrão implausíveis ${ }^{16}$, foi analisado o número de respondentes por categoria de resposta com posterior recategorização para uma estimação mais precisa dos parâmetros ${ }^{17}$.
Para a construção e interpretação da escala, as categorias de resposta foram posicionadas nos níveis de escore nos quais apresentavam probabilidade de acerto maior ou igual 50\%. Esta etapa de ancoragem foi realizada no Excel.

\section{Resultados}

Um total de 1.056 adolescentes, com idade média de, aproximadamente, 13 anos, respondeu ao questionário de violência, sendo $57,4 \%$ do sexo feminino.

No estudo da dimensionalidade, o modelo unidimensional apresentou-se mais adequado segundo os critérios de informação AIC e BIC, justificando a aplicação do modelo unidimensional de resposta gradual de Samejima ${ }^{14}$. A estrutura fatorial com os nove itens explicou 37,4\% da variância. $\mathrm{O}$ alpha de Cronbach padronizado foi igual a 0,67 sugerindo adequada consistência interna dos itens. Além disso, a exclusão de qualquer item não refletiu no aumento no valor de alpha de Cronbach, sugerindo a adequação da estrutura fatorial com nove itens. A qualidade do ajuste do modelo foi confirmada pelos valores adequados dos índices de ajustes incrementais $(\mathrm{CFI}=0,95 ; \mathrm{TLI}=0,94)$ e de ajuste baseado nos resíduos (RMSEA $=0,04)$.

As perguntas "Em relação aos teus pais, quantas vezes você tem a sensação que eles te protegem e te dão carinho?", "Com que frequência você sente que seu pai ou sua mãe ou responsável não gosta de você?", "Você já precisou procurar algum médico porque tinha sido agredido fisicamente, ou alguma outra ajuda porque estava muito machucado?" e "Alguém já molestou você (tocou partes íntimas do seu corpo sem que você concordasse)?" apresentaram estimação mais precisa dos parâmetros quando com duas categorias: não/nunca e sim/alguma vez. A pergunta "Alguma vez, algum de seus colegas te xingou, esculachou, magoou, intimidou ou caçoou, te deixando magoado/ofendido/aborrecido/humilhado?" apresentou estimativas mais precisas quando com quatro categorias de resposta, sendo elas: nunca, raramente, às vezes e frequentemente. A pergunta "Quando seus pais te bateram pela última vez?" apresentou estimação mais precisa dos parâmetros quando com três categorias: nunca, ano passado e último mês. A pergunta "Pessoas da sua família costumam te ofender ou chamar por apelidos humilhantes como feio/lerdo/gordo/entre outros?" apresentou estimação mais precisa quando com três categorias de res- 
posta, sendo nunca, às vezes e frequentemente. As perguntas "Alguém da sua família já atirou alguma coisa em você, como pratos, copos, chinelos, pedras, entre outros objetos?" e "Alguém da sua família já te bateu tão forte que ficaram algumas marcas em seu corpo?" ficaram com as categorias nunca, poucas vezes e muitas vezes.

Para o parâmetro de discriminação $(a)$, os menores valores foram para as perguntas sobre "sensação que pais protegem e dão carinho" $(0,75)$, "ser xingado por colega de escola" $(0,87)$ e "se pais já bateram no adolescente" $(0,97)$. A pergunta sobre "se familiares já bateram no adolescente deixando marcas em seu corpo" foi a que apresentou melhor discriminação $(2,59)$. A pergunta sobre "última vez que pais bateram no adolescente" apresentou menor valor do parâmetro $b\left(b_{2}=-0,68\right)$, sugerindo que a agressão está presente nos níveis em que episódios de violência intrafamiliar e escolar são menos frequentes. As perguntas sobre "se o adolescente precisou procurar algum médico porque tinha sido agredido fisicamente" $\left(b_{2}=3,19\right)$ e "ser xingado por colega na escola" $\left(b_{4}=3,21\right)$ apresentaram maiores valores do parâmetro $b$, indicando que a procura de ajuda e maior frequência de xingamentos por colegas de escola estão presentes entre aqueles indivíduos que sofrem violência intrafamiliar e escolar frequentemente (Tabela 1 ).

A curva característica de cada item está apresentada na Figura 2. A pergunta com baixo valor de discriminação ("Quando seus pais te bateram pela última vez?") está apresentada na Figura 2.3, exemplificando sua característica cumulativa: as categorias de maiores frequências de já ter apanhado dos pais acompanham o aumento do nível de violência. As outras perguntas também apresentaram este perfil de curva característica.

A curva de informação de cada item está apresentada na Figura 3. Os itens "Pessoas da sua família costumam te ofender ou chamar por apelidos humilhantes como feio, lerdo, gordo, entre outros?", "Alguém da sua família já atirou alguma coisa em você, como pratos, copos, chinelos, pedras, entre outros objetos?" e "Alguém da sua família já te bateu tão forte que ficaram algumas marcas em seu corpo?" carregam mais informação do traço latente. A informação conjunta de todos os itens, por sua vez, está apresentada na Figura 4, indicando que a escala de violência intrafamiliar apresenta informação mais precisa para valores acima da média, aproximadamente entre os escores 1 e 3 (Figura 4).

A partir da ancoragem das categorias de resposta de cada uma das nove perguntas foi feita a descrição dos níveis de violência, apresentada no Quadro 1. Assim, um indivíduo com nível de violência maior ou igual a -0.5 e menor do que 1.0 raramente é xingado/caçoado por colegas de escola e apanhou dos pais no ano passado. Outro, com nível maior ou igual a 1.0 e menor do que 2.5 , às vezes é xingado/caçoado por colegas de escola, já sente que pais ou responsáveis não gostam dele e poucas vezes foi agredido fisicamente por familiares. O indivíduo com nível maior ou igual a 2.5 e menor do que 3.5 sempre é xingado/ caçoado por colegas de escola, apanhou dos pais no último mês, muitas vezes foi agredido fisicamente por familiares e já foi molestado.

\section{Discussão}

O presente estudo teve como objetivo desenvolver uma escala para avaliar a violência intrafamiliar e escolar a partir da TRI. Para isso foram analisadas as perguntas do questionário proposto pela Organização Mundial de Saúde que estavam de acordo com o pressuposto da TRI de invariância local. Nove questões foram analisadas e todas se apresentaram adequadas para avaliar a violência intrafamiliar e escolar, permitindo propor e descrever uma escala com três níveis de acordo com o caráter cumulativo da medida.

Além da invariância local, outro pressuposto da TRI corresponde à uni-dimensionalidade. Assim, ao se propor um instrumento de medida, é importante conhecer a sua confiabilidade em medir o que se propõe, iniciando com o estudo das dimensões às quais as perguntas deste novo instrumento estão relacionadas ${ }^{12,13}$. Neste estudo, a análise fatorial comprovou que o questionário está relacionado a uma dimensão dominante, podendo seguir com a aplicação do modelo de resposta gradual de Samejima ${ }^{14}$. Além disso, os índices de ajustes e consistência interna confirmaram a adequação da estrutura fatorial unidimensional.

A TRI permitiu conhecer as características de cada pergunta no continuum de violência intrafamiliar e escolar e descrever em níveis o processo acumulativo do traço latente. Outras métricas de violência no ambiente intrafamiliar e escolar já foram propostas ${ }^{4,18,19}$. Entretanto, se basearam na Teoria Clássica de Medidas, não permitindo conhecer a discriminação nem o posicionamento de cada item no continuum do traço latente. A escala proposta permitiu conhecer as diferentes agressões sofridas pelo indivíduo ou população em um nível de violência. Oliveira et al.? obser- 
Tabela 1. Estimativa dos parâmetros dos itens pelo modelo de Samejima ${ }^{14}$ na escala $(0,1)$. São Paulo, 2016. $(\mathrm{n}=1.056)$

\begin{tabular}{|c|c|c|c|c|c|c|c|c|c|c|c|c|}
\hline Itens & $\%$ NR & $\mathbf{n}_{\text {Cat. 1 }}$ & $\mathbf{n}_{\text {Cat. } 2}$ & $\mathbf{n}_{\text {Cat. } 3}$ & $\mathbf{n}_{\text {Cat. } 4}$ & $\mathbf{n}_{\text {Cat. } 5}$ & $\begin{array}{l}\text { Carga } \\
\text { fatorial }\end{array}$ & $\mathbf{h}^{2}$ & $\begin{array}{c}\mathbf{a} \\
(\mathrm{SE}) \\
\end{array}$ & $\begin{array}{c}\mathbf{b}_{2} \\
(\mathrm{SE}) \\
\end{array}$ & $\begin{array}{c}\mathbf{b}_{3} \\
(\mathrm{SE}) \\
\end{array}$ & $\begin{array}{c}\mathbf{b}_{4} \\
(\mathrm{SE}) \\
\end{array}$ \\
\hline $\begin{array}{l}\text { 1. Alguma vez, algum de } \\
\text { seus colegas te xingou, } \\
\text { esculachou, magoou, } \\
\text { intimidou ou caçoou, } \\
\text { te deixando magoado/ } \\
\text { ofendido/aborrecido/ } \\
\text { humilhado? }\end{array}$ & 0,47 & 410 & 343 & 217 & 61 & 20 & 0,45 & 0,21 & $\begin{array}{r}0,87 \\
(0,09)\end{array}$ & $\begin{array}{r}-0,62 \\
(0,10)\end{array}$ & $\begin{array}{r}1,21 \\
(0,14)\end{array}$ & $\begin{array}{r}3,21 \\
(0,32)\end{array}$ \\
\hline $\begin{array}{l}\text { 2. Em relação aos seus } \\
\text { pais, quantas vezes você } \\
\text { tem a sensação que eles te } \\
\text { protegem e te dão carinho? }\end{array}$ & 0,47 & 672 & 194 & 116 & 38 & 31 & 0,40 & 0,16 & $\begin{array}{r}0,75 \\
(0,11)\end{array}$ & $\begin{array}{r}2,28 \\
(0,31)\end{array}$ & - & - \\
\hline $\begin{array}{l}\text { 3. Quando seus pais te } \\
\text { bateram pela última vez? }\end{array}$ & 2,27 & 377 & 517 & 79 & 32 & 27 & 0,50 & 0,25 & $\begin{array}{r}0,97 \\
(0,10)\end{array}$ & $\begin{array}{r}-0,68 \\
(0,10)\end{array}$ & $\begin{array}{r}2,25 \\
(0,21)\end{array}$ & - \\
\hline $\begin{array}{l}\text { 4. Pessoas da sua família } \\
\text { costumam te ofender } \\
\text { ou chamar por apelidos } \\
\text { humilhantes como feio, } \\
\text { lerdo, gordo, entre outros? }\end{array}$ & 0,76 & 811 & 117 & 83 & 18 & 19 & 0,71 & 0,51 & $\begin{array}{r}1,72 \\
(0,19)\end{array}$ & $\begin{array}{r}1,71 \\
(0,12)\end{array}$ & $\begin{array}{r}2,64 \\
(0,20)\end{array}$ & - \\
\hline $\begin{array}{l}\text { 5. Com que frequência você } \\
\text { sente que seu pai ou sua mãe } \\
\text { ou responsável não gosta de } \\
\text { você? }\end{array}$ & 1,52 & 835 & 99 & 67 & 14 & 25 & 0,56 & 0,31 & $\begin{array}{r}1,14 \\
(0,13)\end{array}$ & $\begin{array}{r}1,52 \\
(0,15)\end{array}$ & - & - \\
\hline $\begin{array}{l}\text { 6. Alguém da sua família } \\
\text { já atirou alguma coisa em } \\
\text { você, como pratos, copos, } \\
\text { chinelos, pedras, entre } \\
\text { outros objetos? }\end{array}$ & 0,47 & 873 & 150 & 25 & 3 & - & 0,68 & 0,47 & $\begin{array}{r}1,59 \\
(0,17)\end{array}$ & $\begin{array}{r}1,40 \\
(0,10)\end{array}$ & $\begin{array}{r}2,97 \\
(0,23)\end{array}$ & - \\
\hline $\begin{array}{l}\text { 7. Alguém da sua família } \\
\text { já te bateu tão forte que } \\
\text { ficaram algumas marcas em } \\
\text { seu corpo? }\end{array}$ & 0,57 & 886 & 147 & 16 & 1 & - & 0,83 & 0,70 & $\begin{array}{r}2,59 \\
(0,30)\end{array}$ & $\begin{array}{r}1,22 \\
(0,07)\end{array}$ & $\begin{array}{r}2,68 \\
(0,17)\end{array}$ & - \\
\hline $\begin{array}{l}\text { 8. Você já precisou procurar } \\
\text { algum médico porque tinha } \\
\text { sido agredido fisicamente, ou } \\
\text { alguma outra ajuda porque } \\
\text { estava muito machucado? }\end{array}$ & 0,47 & 1019 & 19 & 11 & 2 & - & 0,62 & 0,38 & $\begin{array}{r}1,34 \\
(0,23)\end{array}$ & $\begin{array}{r}3,19 \\
(0,38)\end{array}$ & - & - \\
\hline $\begin{array}{l}\text { 9. Alguém já molestou você } \\
\text { (tocou partes íntimas do } \\
\text { seu corpo sem que você } \\
\text { concordasse)? }\end{array}$ & 0,57 & 994 & 43 & 12 & 1 & - & 0,62 & 0,39 & $\begin{array}{r}1,35 \\
(0,19)\end{array}$ & $\begin{array}{r}2,68 \\
(0,27)\end{array}$ & - & - \\
\hline
\end{tabular}

varam uma coocorrência de diferentes formas de violência em estudo de incidências ao longo de uma década, comprovando que as experiências adversas não ocorrem de forma independente ${ }^{7}$. Portanto, o uso de uma escala que permite identificar esta coocorrência é importante em nível de saúde pública, uma vez que possibilita o melhor conhecimento da magnitude do problema.

Neste estudo, apesar do questionário ter sido aplicado para adolescentes, escolares da rede pública de ensino de um município no interior de São Paulo, Brasil, o uso da TRI garante que 
1.1

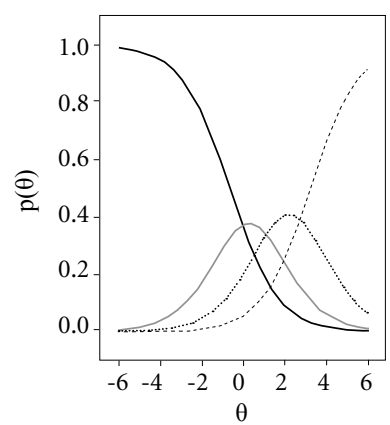

1.4

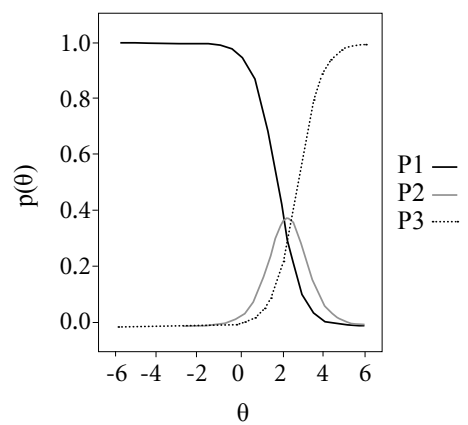

1.7

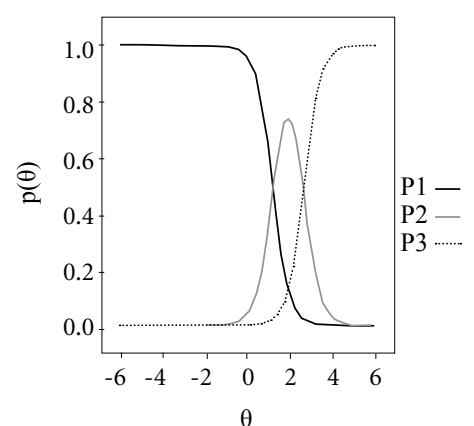

1.2

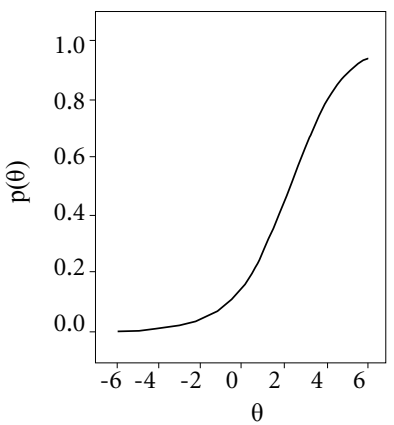

1.5

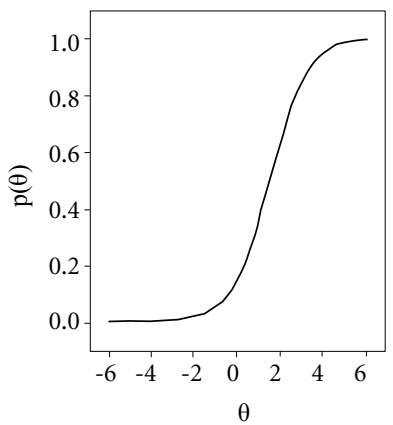

1.8

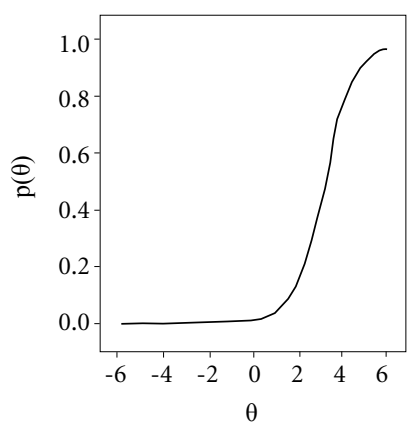

1.3

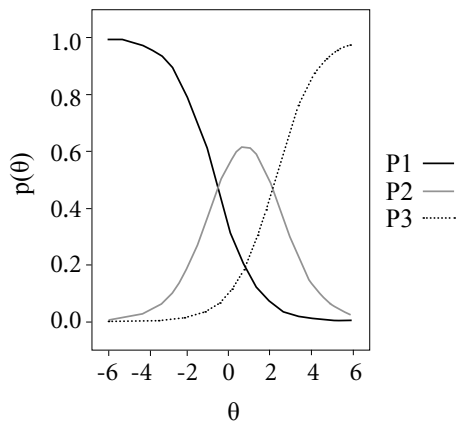

1.6

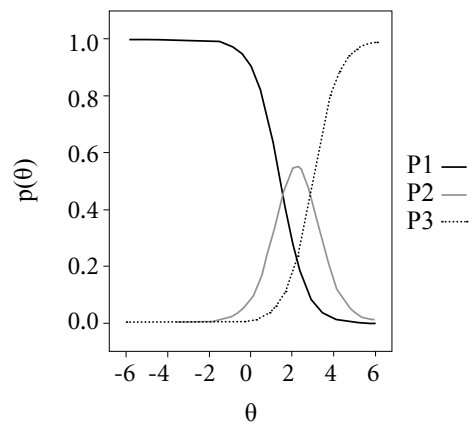

1.9

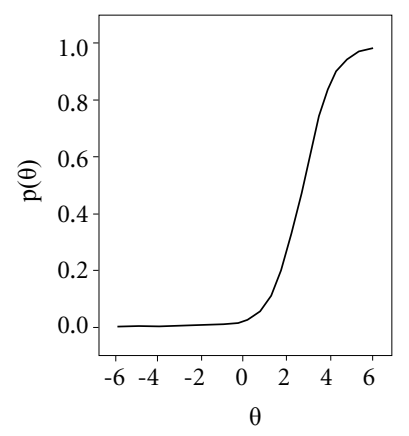

Figura 2. Curva característica de cada um dos itens da escala de violência intrafamiliar e escolar. São Paulo, 2016 $(\mathrm{n}=1056)$.

1.1. Curva característica do item 'Alguma vez, algum de seus colegas te xingou, esculachou, magoou, intimidou ou caçoou, te deixando magoado/ofendido/aborrecido/humilhado?'. 1.2. Curva característica do item 'Em relação aos seus pais, quantas vezes você tem a sensação que eles te protegem e te dão carinho?'. 1.3. Curva característica do item 'Quando seus pais te bateram pela última vez?'. 1.4. Curva característica do item 'Pessoas da sua família costumam te ofender ou chamar por apelidos humilhantes como feio, lerdo, gordo, entre outros?'. 1.5. Curva característica do item 'Com que frequência você sente que seu pai ou sua mãe ou responsável não gosta de você?'. 1.6. Curva característica do item 'Alguém da sua família já atirou alguma coisa em você, como pratos, copos, chinelos, pedras, entre outros objetos?’. 1.7. Curva característica do item 'Alguém da sua família já te bateu tão forte que ficaram algumas marcas em seu corpo?'. 1.8. Curva característica do item 'Você já precisou procurar algum médico porque tinha sido agredido fisicamente, ou alguma outra ajuda porque estava muito machucado?.' 1.9. Curva característica do item 'Alguém já molestou você (tocou partes íntimas do seu corpo sem que você concordasse)?. P1: curva da categoria 1. P2: curva da categoria 2. P3: curva da categoria 3. P4: curva da categoria 4. $\theta$ : escore. P $\theta$ : probabilidade de marcar a categoria. 


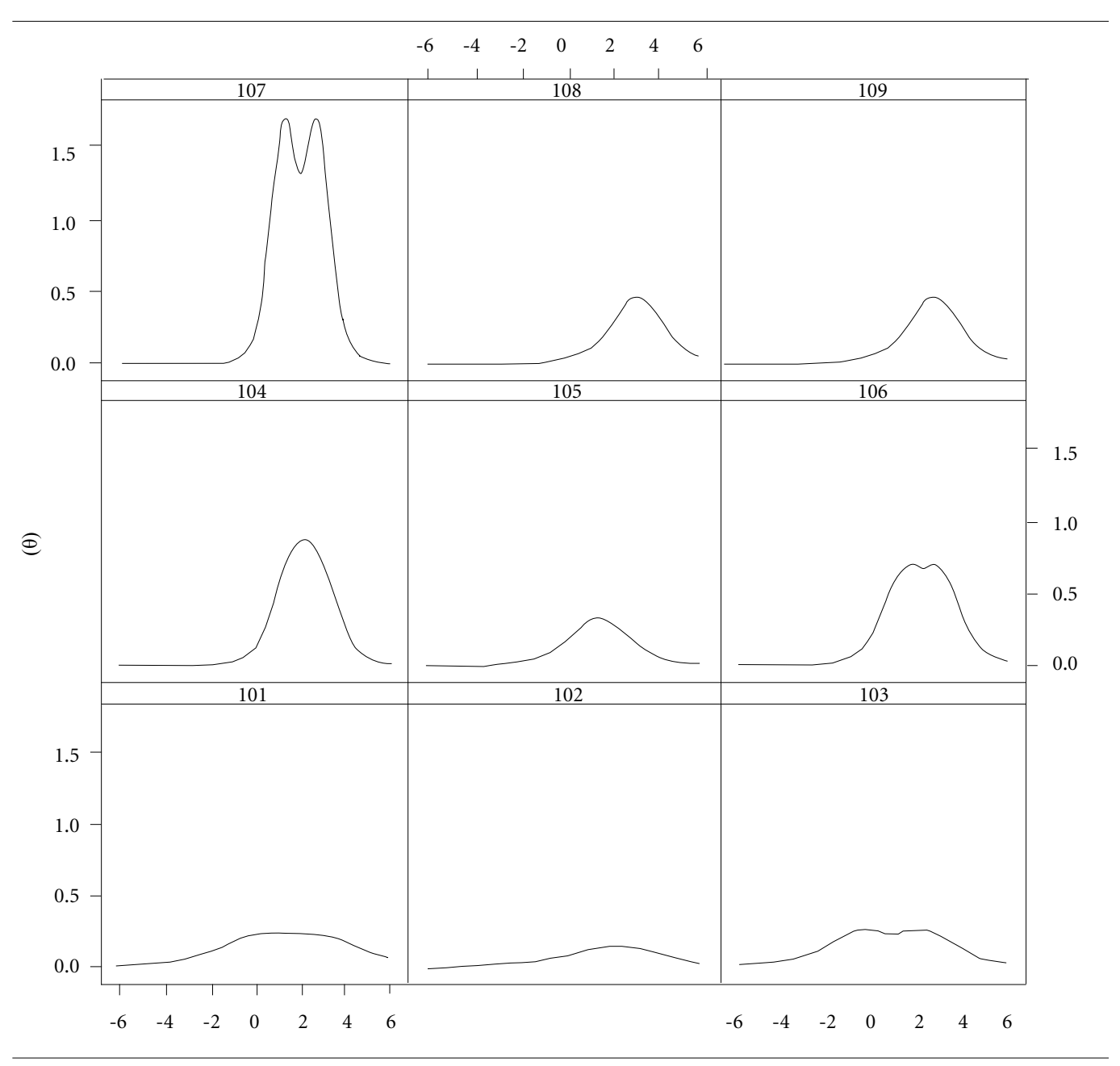

Figura 3. Curva de informação de cada item da escala de violência intrafamiliar e escolar. São Paulo, 2016 ( $\mathrm{n}=$ 1056).

$\theta$ : escore. I $\theta$ : Informação do item por escore. I01. Curva de informação do item 'Alguma vez, algum de seus colegas te xingou, esculachou, magoou, intimidou ou caçoou, te deixando magoado/ofendido/aborrecido/humilhado?'. I02. Curva de informação do item 'Em relação aos seus pais, quantas vezes você tem a sensação que eles te protegem e te dão carinho?'. I03. Curva de informação do item 'Quando seus pais te bateram pela última vez?’. I04. Curva de informação do item 'Pessoas da sua família costumam te ofender ou chamar por apelidos humilhantes como feio, lerdo, gordo, entre outros?'. I05. Curva de informação do item 'Com que frequência você sente que seu pai ou sua mãe ou responsável não gosta de você?’. I06. Curva de informação do item 'Alguém da sua família já atirou alguma coisa em você, como pratos, copos, chinelos, pedras, entre outros objetos?'. I07. Curva de informação do item 'Alguém da sua família já te bateu tão forte que ficaram algumas marcas em seu corpo?'. I08. Curva de informação do item 'Você já precisou procurar algum médico porque tinha sido agredido fisicamente, ou alguma outra ajuda porque estava muito machucado?'. I09. Curva de informação do item 'Alguém já molestou você (tocou partes íntimas do seu corpo sem que você concordasse)?'

a estimação dos parâmetros de discriminação e dificuldade seja independente do universo de respondentes que ele representa ${ }^{8}$. Assim, a escala proposta pode ser aplicada em diferentes grupos de adolescentes.

As perguntas apresentaram parâmetros adequados e a análise dos seus respectivos erros-pa- drão confirma a precisão do processo de estimação. A pergunta sobre "última vez que pais bateram no adolescente" apresentou o menor valor para o parâmetro de dificuldade, localizando a violência física praticada pelos pais no primeiro nível da escala. Este dado indica como este hábito está enraizado nas famílias como uma forma 
de educar os filhos. Entretanto, além de ser uma agressão física, emocional e social, estimula um ciclo dentro das famílias, fortalecendo uma aceitação cultural deste comportamento ${ }^{20}$.

Neste mesmo sentido, a escala indica que, no nível de violência que um adolescente começa a ser agredido fisicamente e emocionalmente por familiares, ele já é xingado por colegas na escola. Quando menos explícitos, alguns atos de violência podem ser banalizados e, muitas vezes, aceitos como brincadeiras de colegas, dificultando iden-

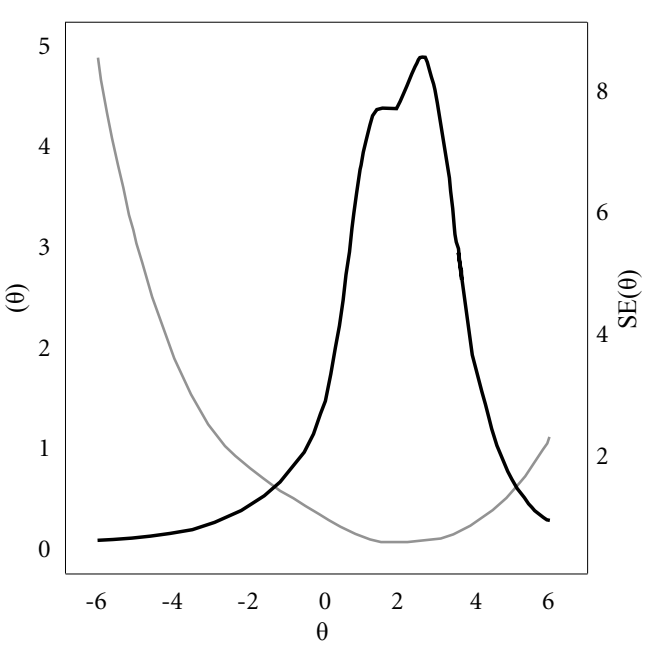

Figura 4. Curva de informação da escala de violência intrafamiliar e escolar. São Paulo, 2016 ( $\mathrm{n}=1056)$. Linha preta: curva de informação da escala. Linha cinza: curva do erro padrão. tificação, controle e prevenção. Além disso, agressões verbais entre colegas, quando não resolvidas, podem resultar em agressões físicas futuras ${ }^{21}$.

$\mathrm{Na}$ escala, conforme aumenta a frequência que os pais batem no adolescente, inicia a percepção de que os pais não gostam dele. E este sentimento está diretamente associado ao nível geral de violência expresso na escala. Em um estudo com escolares da rede pública urbana de um município do estado de Mato Grosso, Brasil, o comportamento violento foi $64 \%$ maior entre aqueles com relacionamento insatisfatório com os pais, indicando uma relação entre a violência intrafamiliar e o comportamento violento dos adolescentes como: porte de armas, envolvimento em brigas e tentativa de suicídio ${ }^{22}$.

$\mathrm{Na}$ escala proposta, o relato de ter sido molestado surge associado a um nível de violência no qual o adolescente não sente mais proteção e carinho dos pais e frequentemente sofre agressões físicas e emocionais de familiares. No contexto brasileiro, dados da Pesquisa Nacional de Saúde do Escolar, realizada em 2015, indicaram que pais, aí incluídos pai/mãe/padrasto/madrasta, e outros familiares foram responsáveis por $12 \% \mathrm{e}$ $20 \%$ das relações sexuais forçadas contra os adolescentes, respectivamente ${ }^{4}$.

$\mathrm{O}$ relato de procura de um médico ou de alguma outra ajuda porque estava machucado relaciona-se com um nível de violência em que o adolescente já foi muitas vezes agredido por familiares. Neste nível as agressões emocionais de colegas de escola são mais frequentes. É importante também considerar a história de agressões físicas na infância e seus reflexos na adolescência, pois estas se relacionam com maior grau de exposição à violência entre pais e/ou criadores ${ }^{23}$.

Quadro 1. Escala de violência intrafamiliar e escolar. São Paulo, 2016.

\begin{tabular}{|c|l|}
\hline Nível & \multicolumn{1}{c|}{ Neste nível... } \\
\hline$-0,5+1,0$ & $\begin{array}{l}\text { O respondente raramente é xingado/caçoado por colegas de escola até ficar magoado/ofendido. } \\
\text { Última vez que apanhou dos pais foi no ano passado. }\end{array}$ \\
\hline $1,0+2,5$ & $\begin{array}{l}\text { O respondente às vezes é xingado/caçoado por colegas de escola até ficar magoado/ofendido e } \\
\text { às vezes é ofendido por pessoas da família. O respondente já sente que pais ou responsáveis não } \\
\text { gostam dele. Familiares poucas vezes já atiraram objetos como pratos, copos e pedras ou já bateram } \\
\text { forte no respondente. }\end{array}$ \\
\hline $2,5+3,5$ & $\begin{array}{l}\text { O respondente sempre é xingado/caçoado por colegas de escola até ficar magoado/ofendido. } \\
\text { Última vez que apanhou dos pais foi no último mês. O respondente frequentemente é ofendido por } \\
\text { familiares. O respondente tem a sensação que pais não o protegem e não dão carinho. Familiares } \\
\text { muitas vezes atiram objetos como pratos, copos e pedras no respondente e batem tão forte no } \\
\text { respondente que ficaram algumas marcas em seu corpo. O respondente já foi molestado. } \\
\text { O respondente já teve que procurar médico devido agressão física. }\end{array}$ \\
\hline
\end{tabular}


A análise das curvas de informação de cada pergunta destaca a qualidade da escala em avaliar atos de violência praticada por familiares. As curvas indicam que perguntas "Pessoas da sua família costumam te ofender ou chamar por apelidos humilhantes como feio, lerdo, gordo, entre outros?", "Alguém da sua família já atirou alguma coisa em você, como pratos, copos, chinelos, pedras, entre outros objetos?" e "Alguém da sua família já te bateu tão forte que ficaram algumas marcas em seu corpo?" carregam mais informação do traço latente.

A análise da curva de informação do teste sugere que a escala aqui apresentada tem maior aplicabilidade para populações em risco. Assim, diante dos altos indicadores de violência intrafamiliar e escolar, bem como dos efeitos das agressões a curto e longo prazo, é útil dispor de instrumento população-específico, bem como preciso e curto. Em geral, vítimas de agressões apresentam dificuldade e mesmo resistência para relatar os episódios. Um instrumento com menor número de perguntas provavelmente apresentará respostas mais fidedignas ${ }^{24}$.

A TRI também permite que sejam incluídas outras questões a partir da técnica de equalização, mantendo os parâmetros de discriminação e dificuldade estimados neste estudo. Assim, as novas perguntas serão posicionadas na escala tendo como referência as nove já analisadas. Esta inclusão de perguntas proporcionará obter mais informação para outros níveis da escala, sem necessariamente, refletir em um maior número de perguntas que um indivíduo tenha que respon$\operatorname{der}^{25}$.

Este estudo apresenta algumas limitações. O processo de estimação dos parâmetros de discriminação e dificuldade indicou a necessidade de recategorização das respostas. Apesar de estimativas adequadas após esta recategorização, o baixo percentual de respostas em algumas categorias pode estar associado a características da amostra, localizada em município de região afluente no estado de São Paulo. Entretanto, a aplicação da TRI garante que esta estimação seja independente do conjunto de respondentes. Mesmo com essas limitações, os baixos valores de erros-padrão das estimativas, bem como a curva de informação, sugerem o desempenho preciso da escala em populações sob o risco de violência intrafamiliar e escolar.

\section{Conclusões}

O presente estudo é o primeiro a propor uma escala de violência considerando as informações fornecidas pela TRI. Foi utilizado o questionário proposto pela Organização Mundial de Saúde para avaliar a violência intrafamiliar e escolar. A análise da dimensionalidade confirmou que as perguntas avaliam o mesmo traço latente. A TRI acrescentou informações sobre as características de cada pergunta, permitindo identificar aquelas que melhor discriminam os níveis de violência intrafamiliar e escolar. A identificação dos parâmetros de dificuldade possibilitou posicionar cada pergunta no continuum avaliado e observar a banalização de alguns tipos de violência. Bater nos filhos como medida educativa e agredir verbalmente colegas de escola apresentaram-se no nível mais baixo da escala. Assim, a escala constitui-se uma nova abordagem para avaliar o nível de violência intrafamiliar e escolar, principalmente em populações em risco, considerando não apenas agressões de ordem física, mas, também, sexual, psicológica ou por negligência. Portanto, o desenvolvimento da escala pode orientar a avaliação e implementação de políticas públicas no âmbito da violência intrafamiliar $\mathrm{e}$ escolar, bem como estimular outros estudos psicométricos para incorporar novas perguntas na escala apresentada, ampliando sua cobertura do traço latente. 


\section{Colaboradores}

TSS Santos participou da concepção, estruturação e análise dos dados, escreveu o manuscrito e participou da sua revisão crítica e aprovação da versão a ser publicada. DF Andrade participou da concepção, estruturação e análise dos dados, participou da revisão crítica do manuscrito e aprovação da versão a ser publicada. AC Bornia participou da concepção, estruturação e análise dos dados, participou da revisão crítica do manuscrito e aprovação da versão a ser publicada. WL Conde participou da concepção, estruturação e análise dos dados, participou da revisão crítica do manuscrito e aprovação da versão a ser publicada. BS Villar participou da concepção, estruturação e análise dos dados, participou da revisão crítica do manuscrito e aprovação da versão a ser publicada.

\section{Referências}

1. World Health Organization (WHO). WHO Global Consultation on Violence and Health. Violence: a public health priority. Geneva: WHO; 1996.

2. Krug EG, Dahlberg LL, Mercy JA, ZWI AB, Lozano R. World report on violence and health. Geneva: WHO; 2002.

3. Minayo MCS, Souza ER. Violence and health care as an interdisciplinary field and an arena for collective action. Hist Cien Saude-Manguinhos 1997-1998; 6(3):513-531.

4. Instituto Brasileiro de Geografia e Estatística (IBGE). Coordenação de População e Indicadores Sociais. Pesquisa Nacional de Saúde do Escolar. Brasília: IBGE; 2016.

5. Stoltenborgh M, Bakermans-Kranenburg MJ, Van Ijzendoorn MH. The neglect of child neglect: a meta-analytic review of the prevalence of neglect. Soc Psychiatry Psychiatr Epidemiol 2013; 48(3):345-355.

6. World Health Organization (WHO). Global and regional estimates of violence women: prevalence and health effects of intimate partner violence and non-partner sexual violence. Geneva: WHO; 2013.

7. Oliveira JR, Costa COM, Amaral MTR, Santos CA, Assis SG, Nascimento OC. Violência sexual e coocorrências em crianças e adolescentes: estudo das incidências ao longo de uma década. Cien Saude Colet 2014; 19(3):759-771.

8. Araújo EAC, Andrade DF, Bortolotti SLV. Teoria da Resposta ao Item. Rev Esc Enferm USP 2009; 43:10001008.

9. Andrade DF, Tavares HR, Valle RC. Teoria de resposta ao item: conceitos e aplicações. São Paulo: ABE; 2000.

10. Butchard A, Phinney A. Preventing Child Maltreatment: a guide to taking action and generating evidence. Geneva: WHO, Internacional Society of Child Abuse and Neglect; 2006.

11. Nutrisim: Sistema de Monitoramento da Saúde-Nutrição e alimentação do escolar. [programa de computador]. Versão 1. São Paulo: USP; 2011. Disponível em http://www.fsp.usp.br/nutrisim

12. Hair JF, Black WC, Babin BJ, Anderson RE, Tatham RL. Análise fatorial. In Hair JF, Black WC, Babin BJ, Anderson RE, Tatham RL. Análise multivariada de dados. Porto Alegre: Bookman; 2009.

13. Brown TA. Introduction to Confirmatory Factor Analysis. In: Brown TA. Confirmatory Factor Analysis for Applied Research. New York: The Guilford Press; 2015.

14. Samejima FA. Estimation of latent ability using a response pattern of graded scores. Psychometric Monograph 1969; 34(4):1-97.

15. Tezza R, Bornia AC, Andrade DF. Measurement web usability using item response theory: principles, features and opportunities. Interacting Computers 2011; 23(2):167-175.

16. Chernyshenko OS, Stark S, Chan K-Y, Drasgow F, Williams B. Fitting Item Response Theory Models to two personality inventories: issues and insights. Multivariate Behavioral Res 2001; 36(4):523-562.

17. Menogon LS. Mensuração de conforto e desconforto em poltrona de aeronave pela teoria de resposta ao item [tese]. Florianópolis: Universidade Federal de Santa Catarina; 2013. 
18. Silveira ALS, Grassi-Oliveira R. Validação semântica da ISPCAN Child Abuse Screening Tools (ICAST) em português brasileiro. Trends Psychiatry Psychother 2016; 38(2):105-110.

19. Stelko-Pereira AC, Williams LCA, Freitas LC. Validade e consistência interna do questionário de investigação de prevalência de violência escolar - versão estudantes. Aval Psicol 2010; 19(3):403-411.

20. Silva PA. Notificação da violência intrafamiliar contra crianças e adolescentes como exercício de poder e resistência [tese]. Rio Grande: Escola de Enfermagem; 2015.

21. Camacho LMY. As sutilezas das faces da violência nas práticas escolares de adolescentes. Educ Pesq 2001; 27(1):123-140.

22. Castro ML, Cunha SS, Souza DPO. Comportamentos de violência e fatores associados entre adolescentes de Barra do Garças, MT. Rev Saúde Pública 2011; 45(6):1054-1061.

23. Zanoti-Jeronymo DV, Zaleski M, Pinsky I, Caetano R, Figlie NB, Laranjeira R. Prevalência de abuso físico na infância e exposição à violência parental em uma amostra brasileira. Cad Saúde Pública 2009; 25(11):2467-2479.

24. DeVellis RF. Guidelines in scale development. In: DeVellis RF. Scale development: theory and applications. Los Angeles: SAGE; 2017.

25. Cella D, Riley W, Stone A, Rothrock N, Reeve B, Yount S, Amtmann D, Bode R, Buysse D, Choi S, Cook K, Devellis R, DeWalt D, Fries JF, Gershon R, Hahn EA, Lai JS, Pilkonis P, Revicki D, Rose M, Weinfurt $\mathrm{K}$, Hays R. The patient-reported outcomes measurement information system (PROMIS) developed and tested its first wave of adult self-reported health outcome item banks: 2005-2008. J Clin Epidemiol 2010; 63(11):1179-1194.

Artigo apresentado em 21/06/2018

Aprovado em 13/12/2018

Versão final apresentada em 15/12/2018 